\section{Response to: 'Metabolic and cardiovascular benefits of hydroxychloroquine: exploration in a wider population at high CV risk' by Pareek et al}

In their letter to the editor, Pareek et al raised some issues regarding our recent paper. ${ }^{12}$ We appreciate their interest in our study and their positive comments.

Pareek et al highlight the fact that several studies addressing the metabolic effect of hydroxychloroquine (HCQ) have not been included in our meta-analysis due to our stringent inclusion criteria (HCQ users vs non-users in patients with rheumatoid arthritis (RA)). We acknowledge this point. However, we believe that to establish and to follow such strict inclusion criteria is important in a meta-analysis in order to reduce to a minimum heterogeneity of the pooled results. Indeed, there was no significant heterogeneity among studies that were included in our work. ${ }^{2}$

Two studies mentioned by Pareek et al regarding reduced diabetes incidence with HCQ were not included in our meta-analysis. This was due to heterogeneous study population for the paper by Solomon $e t \mathrm{al}^{3}$ and to a publication date posterior to the end of our meta-analysis timeline for the paper by Ozen et al. ${ }^{4}$ Anyway, the data are consistent with our results and strengthen our conclusions.

Focusing only on RA was a willingness, because by contrast to other diseases such as lupus, HCQ is not clearly recommended in RA due to its rather low efficacy on arthritis. ${ }^{5}$ Getting proofs that it could have interesting benefit for patients with RA through its metabolic effect could have an effective impact in practice. Anyway, as indicated by Pareek et al, the beneficial effect of HCQ on cardiovascular risk factors that we found in our meta-analysis has also been noted in chronic inflammatory conditions other than RA, notably lupus.

Thus, even if for methodological reasons we did not present in our article all the studies exploring the metabolic effect of HCQ, it appears that, as stated by Pareek et al, evidence supporting the metabolic and cardiovascular benefits of HCQ in inflammatory rheumatic diseases, including RA, begin to be quite strong in the literature.

\section{Charlotte Hua, Claire Rempenault, Bernard Combe}

Rheumatology department, Lapeyronie Hospital, Montpellier University, Montpellier, Languedoc-Roussillon, France

Correspondence to Dr Charlotte Hua, Département de Rhumatologie, CHU Lapeyronie, 191 Av. du Doyen Gaston Giraud, 34295 Montpellier cedex 5, France; c-hua@chu-montpellier.fr

Contributors All authors have contributed equally to this work.

Competing interests None declared.

Provenance and peer review Commissioned; internally peer reviewed.

(c) Article author(s) (or their employer(s) unless otherwise stated in the text of the article) 2019. All rights reserved. No commercial use is permitted unless otherwise expressly granted.

\section{Check for updates}

To cite Hua C, Rempenault C, Combe B. Ann Rheum Dis 2019;78:e22.

Received 17 October 2017

Accepted 23 October 2017

Published Online First 1 November 2017

\section{S Linked}

http://dx.doi.org/10.1136/annrheumdis-2018-213157

Ann Rheum Dis 2019;78:e22. doi:10.1136/annrheumdis-2017-212557

\section{REFERENCES}

1 Pareek A, Purkait I, Mehta RT, et al. Metabolic and cardiovascular benefits of hydroxychloroquine: exploration in a wider population at high CV risk. Ann Rheum Dis 2017:annrheumdis-2017-212499.

2 Rempenault C, Combe B, Barnetche T, et al. Metabolic and cardiovascular benefits of hydroxychloroquine in patients with rheumatoid arthritis: a systematic review and meta-analysis. Ann Rheum Dis 2017:annrheumdis-2017-211836 (Published online first: 25 Sep 2017)

3 Solomon DH, Massarotti E, Garg R, et al. Association between disease-modifying antirheumatic drugs and diabetes risk in patients with rheumatoid arthritis and psoriasis. JAMA 2011;305:2525-31.

4 Ozen G, Pedro S, Holmqvist ME, et al. Risk of diabetes mellitus associated with diseasemodifying antirheumatic drugs and statins in rheumatoid arthritis. Ann Rheum Dis 2017;76:848-54.

5 Smolen JS, Landewé R, Bijlsma J, et al. EULAR recommendations for the management of rheumatoid arthritis with synthetic and biological disease-modifying antirheumatic drugs: 2016 update. Ann Rheum Dis 2017;76:960-77. 